Article

\title{
Isolation and Characterisation of Probiotics for Antagonising Cariogenic Bacterium Streptococcus mutans and Preventing Biofilm Formation
}

\author{
Pei-Pei Lin ${ }^{1}$, You-Miin Hsieh ${ }^{2}$, Cheng-Chih Tsai ${ }^{3, *}$ \\ ${ }^{1}$ Department of Culinary Arts, De Lin Institute of Technology, Taipei City 23654, Taiwan \\ ${ }^{2}$ Department of Food and Nutrition, Providence University, Taichung City 43302, Taiwan \\ ${ }^{3}$ Department of Food Science and Technology, HungKuang University, Taichung City 43302, Taiwan \\ * Correspondence: Fax: 886-4-26319176, Tel: 886-4-26318652\#5083, E-mail: tsaicc@sunrise.hk.edu.tw
}

\begin{abstract}
Consumption of refined foods and beverages high in sugar make the teeth susceptible to the formation of biofilm, and lead to dental caries and diseases of the oral cavity such as periodontitis and periodontal disease. The aim of the present study was to determine the ability of selected probiotics to inhibit growth and biofilm formation by the cariogenic bacterium Streptococcus mutans in vitro. We screened strains of latic acid bacteria (LAB) $(n=120)$ from the Bioresources Collection and Research Center (BCRC), saliva of healthy adults and infant stool. The antimicrobial activity of LAB in vitro was evaluated by agar spot culture and co-culture of the S. mutans strains. We determined the effect of heating and dilution factors (2- and 4-fold) on the antagonistic activity of LAB. Antagonistic substances in the spent culture suspensions (SCS) of $\mathrm{LAB}$ were precipitated by extraction with ammonium sulphate and chloroform to characterise the protein and lipophilic fractions. Results of co-culturing show that the SCS of the three LAB strains (Lactobacillus pentosus 13-1, 13-4 and Lactobacillus crispatus BCRC 14618) subjected to heat treatment showed significantly high antimicrobial activity. We found that substances produced by L. pentosus 13-4 which have the potential to exhibit antimicrobial properties might be lipophilic proteins. Additionally, we infer that the mechanism of reducing biofilm formation by Lactobacillus strains is associated with sucrose-dependent cell-cell adhesion and the gtfC level of glucosyltransferases (Gtfs) in the biofilm. Native LAB strains screened in our study may be used in chewing gums and other processed foods for preventing tooth decay.
\end{abstract}

Keywords: dental caries; Streptococcus mutans; lactic acid bacteria; biofilm; glucosyltransferases

\section{Introduction}

Dental caries is the most common oral infectious disease caused by a cluster of bacteria involved the initial biofilms formation and subsequent carcinogenesis [1]. Studies have shown that $60-90 \%$ of all schoolchildren have dental caries. Among middle-aged adult Americans, $5-20 \%$ are affected by severe periodontitis, a disease that affects the supporting structures of the teeth, while $46 \%$ of American adults have gingivitis [2, 3]. Poor oral health has also been related to diseases such as stomach ulcers, gastric cancer, and cardiovascular disease [4,5]. The key to prevention and treatment of these oral diseases is the effective control of oral pathogens and biofilms. Many antimicrobial agents such as chlorhexidine, hexetidine, delmopinol and phenolic compounds have the ability to inhibit biofilm formation and affect bacterial metabolism. However, these compounds have undesirable side effects such as vomiting, diarrhoea, drug resistance and staining of the teeth [6]. Therefore, it is necessary to develop an efficient biofilm deterrent that exhibits few or no side effects [7]. 
Streptococcus mutans is the most important causative pathogen of dental caries [8]. S. mutans can express glucosyltransferases (GTFs) that catalyze the synthesis of glucans, which play a key role in S. mutans sucrose-dependent adhesion and biofilm formation $[9,10]$. Three distinct $g t f$ genes that encode GTFs have been cloned, including $g t f B, g t f C$ and $g t f D$. Specifically, the $g t f B$ and $g t f C$ genes encode enzymes that produce water-insoluble glucans, contributing to biofilm formation [11, 12]. In previous review, Prakash et al. [13] established that probiotics may be used as a remedy for a number of gastrointestinal-tract (GIT) disorders. Since the oral cavity is a continuation of the GIT, probiotics may be administered as oral therapeutics. A recent study has shown that the oral administration of probiotics may benefit oral health by preventing the growth of harmful microbiota or by modulating mucosal immunity in the oral cavity [14]. Some investigators have found probiotics could inhibit the biofilm formation by reducing the expression of $g t f$ genes [15-17].

Administration of probiotics as oral biotherapeutics is an alternative approach to combat infections that uses harmless bacteria to displace pathogenic microorganisms. There are a limited number of studies showing that some probiotic cultures may help improve dental health and promote the antimicrobial activity of lactobacilli. Thus, the aim of the present study was to isolate and screen probiotic lactic acid bacteria (LAB) to investigate their ability to inhibit biofouling and growth of Streptococcus mutans in vitro. It also aimed to demonstrate the potential use of these strains as probiotics for promoting oral health and preventing dental caries.

\section{Results}

\subsection{Evaluation of the antimicrobial activity of $L A B$}

One hundred-twenty isolates were selected to evaluate the antagonistic activity. Thirteen of the strains demonstrated antimicrobial activity against the gram-positive indicator microorganism $S$. mutans BCRC 15257 in the spot-on-the-lawn antagonism method. The size of the inhibition zone differed slightly among the LAB strains of various origins and species (Table 1). A total of LAB strains with 2 from human saliva, 2 from infant stools and 3 from BCRC samples produced larger inhibition zones, especially Lactobacillus species (5 strains). Another 6 LAB strains from human saliva and BCRC strains produced smaller inhibition zones.

\subsection{Inhibition assay of $S$. mutans by $L A B-S C S$}

Thirteen LAB strains ( 5 from BCRC, 2 from infant stool and 6 from saliva) were tested for antimicrobial activity against $S$. mutans by the spot-on-the-lawn antagonism method. We also performed the co-incubation assay for inhibition of $S$. mutans growth using LAB-SCS by measuring turbidity of the culture to determine microbial growth. Results of the co-incubation LAB-SCS of the 13 strains and S. mutans BCRC 15257 showed that these strains could inhibit S. mutans growth effectively (Table 1). Extended incubation (24 h) with salivary LAB (strains 11, 13-1 and 13-4), with LAB from infant stools (strains LA05 and Bb12) and with LAB from BCRC (strains LCR01, Bbr-1 and LSS01) led to lower OD (Table 2), showing a powerful inhibitory effect on S. mutans. However, incubation with salivary LAB (strains 12-1, 12-2 and 40-2) and BCRC 11080 and 12194 resulted in OD values at $24 \mathrm{~h}$ and did not inhibit the growth of $S$. mutans.

\subsection{Time-kill assay of LAB-SCS}

In the time-kill assay, strains 13-1, 13-4 and L. crispatus BCRC 14618 (LCR01) showed stronger bactericidal activity against $S$. mutans than did other LAB strains after $24 \mathrm{~h}$ of incubation (Table 3). A noticeable decline from 8 to $6 \log$ units in viable counts of S. mutans BCRC 15257 was observed after $6 \mathrm{~h}$ of incubation with the SCS of strains 13-1, 13-4 and LCR01. In contrast, the viable counts of S. mutans increased after 12 and $24 \mathrm{~h}$ incubation with the SCSs of LAB strains 13-1 and 13-4 (Figure 1, 2 and 3). Therefore, the SCSs of LAB strains 13-1, 13-4 and LCR01 from the $24 \mathrm{~h}$ culture were selected to determine their antimicrobial activity towards $S$. mutans. Treatments were performed by using different preparations of LAB-SCS, namely, neutralised LAB-SCS ( $\mathrm{pH}$ 7.2), diluted LAB-SCS (2- and 4-fold), heat-treated LAB-SCS $\left(30 \mathrm{~min}\right.$ at $\left.100^{\circ} \mathrm{C}\right)$ and LAB-SCS treated with of amylase. 
Results show that no viable cells of $S$. mutans BCRC 15257 were recovered after co-incubation with heat-treated SCSs of strains 13-1, 13-4 and LCR01- for 12 and $24 \mathrm{~h}$ (a decrease in 7 to 8 log units, Figure 1 and 2). A 2-fold dilution of LAB-SCS had stronger inhibitory activity showed did a 4-fold dilution, showing concentration dependence of the activity (Figure 1). The inhibitory activity of SCSs of 13-1, 13-4 and LCR01 against S. mutans BCRC 15257 was lost when they were neutralised to $\mathrm{pH} 7.2$ (Figure 1B and 2). These results suggest that the bactericidal activity of LAB-SCS was mediated by the $\mathrm{pH}$ value of the solution. No significant differences between the bactericidal activities of LAB-SCS treated with amylase and of untreated SCS were observed (Figure 2). The SCS of strains 13-1, 13-4 and LCR01 showed similar inhibitory activities against S. mutans BCRC 15254 and 15255 (Figure $3 \mathrm{~A}$ and B).

From the 10 healthy participants, 10 Lactobacillus strains were isolated, with 2 strains (13-1 and 13-4) having strong antimicrobial activity. Therefore, it was necessary to identify Lactobacillus by using API 50CHL before using them as probiotics. Two strains (13-1 and 13-4) were identified as $L$. pentosus using API 50CHL.

\subsection{Characteristics of the antibacterial activity}

Characteristics of the antibacterial activity of heat-treated SCS of L. pentosus 13-4 and L. crispatus LCR01 were studied (Table 4). Proteins present in both SCS precipitated with ammonium sulphate had a small effect on the activity; viable counts of $S$. mutans decreased to $1.5 \log$ units $(P<0.001)$ compared with those of $S$. mutans in BHI broth alone after $24 \mathrm{~h}$ of contact. Activity was found in the lipophilic fraction extracted from the heat-treated SCS of LAB strains with chloroform-methanol (1:1). The SCS of L. pentosus 13-4, in particular, decreased viable counts to $2 \log$ units $(P<0.001)$ after $24 \mathrm{~h}$ of contact.

\subsection{Calcium release from rat teeth}

We conducted a preliminary study to determine the degradation of teeth by lactobacilli. The effect of $S$. mutans was negligible within $12 \mathrm{~h}$ of incubation, but the calcium release increased considerably (Figure 4). After $24 \mathrm{~h}$ of incubation, the concentration of calcium released from teeth caused by $S$. mutans BCRC 15254 and BCRC 15255 was $5.81 \mathrm{mg} / \mathrm{dl}(1.4 \mathrm{mmol} / \mathrm{L})$ and $2.18 \mathrm{mg} / \mathrm{dl}(0.5 \mathrm{mmol} / \mathrm{L})$, respectively. In contrast, the calcium release caused by heat-treated SCS of L. pentosus 13-4 and of $L$. crispatus BCRC 14618 (LCR01) was negligible (0.09 and $0.04 \mathrm{mg} / \mathrm{dl}$, respectively) at $24 \mathrm{~h}$ of incubation (Figure 4). Notably, calcium release caused by S. mutans BCRC 15254 and BCRC 15255 decreased markedly after $24 \mathrm{~h}$ co-incubation with heat-treated SCS of L. pentosus 13-4 or with heat-treated SCS of L. crispatus LCR01.

\subsection{Effects of L. pentosus 13-4 and L. crispatus LCR01 on biofilm formation by S. mutans}

As demonstrated in Figure 5B and C, heat-treated SCS of L. pentosus 13-4 and L. crispatus LCR01 showed substantial anti-bio-fouling activity compared with the BHI control by minimising attachment and biofilm production (Figure 5). Consequently, a microtitre-plate format assay was used to determine whether these LAB strains could adversely affect biofilm development and accumulation. We examined biofilm formation by S. mutans BCRC 15255 on the tooth surface in the presence of $1 \%$ and $2 \%$ sucrose $(\mathrm{w} / \mathrm{v})$ for $48 \mathrm{~h}$ by co-incubation or post-incubation with $L$. pentosus 13-4 and L. crispatus LCR01. Co-incubation or post-incubation with live cells of both LAB strains in the presence of $1 \%$ and $2 \%$ sucrose significantly diminished the accumulation of biofilm compared with that in the BHI control $(P<0.001)$ (Figure 6). Treatments with both strains led to $\sim 80-90 \%$ and $\sim 40-50 \%$ reduction in biofilm formation (lower OD values) at co-incubation and post-incubation, respectively $(P<0.001)$. Co-incubation with the SCS and heat-treated SCS of both strains in the presence of $1 \%$ sucrose led greater reduction of biofilm formation at that achieved with post-incubation. Inhibition of biofilm formation upon LAB-SCS treatment at a sucrose concentration of $2 \%$ was insignificant (Figure 6). Additionally, dead cells of L. pentosus 13-4 and L. crispatus LCR01 did not reduce biofilm formation. 


\subsection{Effects of $L A B-S C S$ on $g t f B$ and gtfC expression}

Results show that the inhibitory effect of heat-treated LAB-SCS of both strains in the immobilised state on the expression of the gtfC gene was apparent. Heat-treated SCS of L. crispatus LCR01 inhibited the expression of the $g t f C$ gene. Similarly, the inhibitory activity of its planktonic cells was lower than that of cells in the immobilised states (Figure 7 and 8B). The activity of GTF in the expression of $g t f C$ was not eliminated by treatment with $L$. pentosus 13-4 cell culture, but was inhibited by treatment with L. crispatus LCR01 cell culture (Figure 8B). There was no difference in $g t f B$ gene expression between the $S$. mutans control (prepared by addition of $2 \%$ sucrose to the BHI medium), heat-treated LAB-SCS and culture of LAB in immobilised biofilms (Figure 8A).

\section{Discussion}

Lactobacilli comprise approximately $1 \%$ of cultivable oral microflora [18]. Most oral lactobacilli can inhibit the growth of pathogens causing periodontitis and caries in vitro [19]. Aggregation assays and growth-inhibition assays are useful tools for screening probiotic candidates with potential capability to prevent caries [20]. Thirteen strains demonstrated antimicrobial activity against $S$. mutans BCRC 15257 in the spot-on-the-lawn antagonism method. The methods used in this study had previously been used for screening purposes and were proven to be simple and robust in comparison with more sophisticated techniques. Subsequently, we used the co-incubation assay to confirm that the SCSs of eight LAB strains could decrease the viable counts of $S$. mutans. Results of this assay indicate that most of the oral Lactobacillus strains isolated from saliva of healthy adults had higher antimicrobial activity against putative oral pathogens isolated from infant stools.

SCSs of eight LAB strains showed different bactericidal activities in the time-kill assay. Strains 13-1 and 13-4 from saliva and L. crispatus BCRC 14618 (LCR01) showed stronger bactericidal activity compared with other LAB strains against $S$. mutans after incubation for $24 \mathrm{~h}$. Salivary lactobacilli strains 13-1 and 13-4 which possessed strong antimicrobial abilities were identified as L. pentosus. Interestingly, Teanpaisan and Dahlen [21] reported that the most common lactobacilli species recovered from saliva were Lactobacillus fermentum, L. rhamnosus, L. salivarius, L. casei, L. acidophilus and L. plantarum, and did not include L. pentosus. The reason for this exclusion might be closely correlate to race, living environment, health status, and food intake of the host.

Inhibition of most microorganisms by $\mathrm{LAB}$ could be due to the production of $\mathrm{H}_{2} \mathrm{O}_{2}$, organic acids, carbon dioxide, diacetyl, acetaldehyde, reuterin, specific bacteriocin, and nonbacteriocin, as well as antioxidant activity [22, 23]. The SCSs of L. pentosus 13-4 and L. crispatus LCR01 cultured in MRS broth for $20 \mathrm{~h}$ had $\mathrm{pH}$ values of 4.30 and 4.34, respectively. Neutralisation of these SCSs to $\mathrm{pH} 7.0$ eliminated the antimicrobial activity. Oral digestive enzymes such as amylase did not reduce the inhibitory effect of LAB-SCS. Dependence of the viability of S. mutans on the concentration of LAB was probably due to the dilution of inhibitory compounds in the LAB-SCS during incubation with L. pentosus 13-4 and L. crispatus LCR01. However, it is should be noted that heat treatment of LAB-SCS enhanced its antagonistic activity. Results for the SCSs of L. pentosus 13-4 and L. crispatus LCR01 show that the $\mathrm{pH}$ value of these strains did not change after heating $(\mathrm{pH} 4.23$ and 4.27, respectively); however, the level of lactic acid increased $(0.592 \mathrm{~g} / 1$ to $0.996 \mathrm{~g} / \mathrm{l}$ and $0.607 \mathrm{~g} / 1$ to 1.250 $\mathrm{g} / \mathrm{l}$, respectively). Therefore, the bactericidal effect might be due to the production of organic acids concurrently with production of bacteriocin-like proteins, which are active under acidic conditions [24].

Our results for L. pentosus 13-4 and L. crispatus LCR01 are consistent with a mechanism of action dependent on production of antimicrobial compounds. We found provided evidence that the activity of strains 13-4 and LCR01 in vitro resulted from antimicrobial compounds present in the SCS, suggesting that these compounds are secreted. We found that strains 13-4 and LCR01 produced an antibacterial lipophilic factor. Similarly, Busarcevic et al. [25] also found that purification of bacteriocin from the oral strain L. salivarius BGHO1 resulted in antagonism of the growth of oral pathogens. Tao et al. [26] demonstrated that a small, molecular weight peptide 
synthesised by the probiotic LGG induced secretion of acidic, heat-stable, cytoprotective, heat shock proteins in murine intestinal epithelial cells. Thus, potential antimicrobial compounds produced by these candidate probiotics against $S$. mutans could be related to lipophilic and acidic factors.

On the other hand, some studies suggested that $L$. salivarius has cariogenic potential $[27,28]$ and that L. rhamnosus, which ferments sucrose slowly and produces lactic acid, increases the risk of dental caries and leads to the demineralisation of tooth enamel. Calcium release due to the presence of $S$. mutans increased during incubation, but was negligible in the presence of L. pentosus 13-4 and L. crispatus LCR01 during $24 \mathrm{~h}$ of incubation. Nikawa et al. [29] reported similar results. Interestingly, we found that co-incubation of S. mutans with L. pentosus 13-4 or L. crispatus LCR01 suppressed calcium release in the presence of $S$. mutans. Thus, LAB strains may affect both cell-to-cell and cell-to-surface interactions.

S. mutans tends to form biofilms to survive in its environment. S. mutans cells assemble into colonies attached to dental surfaces and form a matrix-embedded biofilm in an environment with simple sugar [30]. Anti-fouling is the process of removing or preventing accumulation of the biofilm. In the present study, there were significant differences in characteristics of biofilm formation between environments with different sucrose concentration and different LAB treatments. Biofilm production by $S$. mutans grown in BHI medium supplemented with $1 \%$ sucrose was notably affected by L. pentosus 13-4, L. crispatus LCR01 and their heat-treated SCSs alone, compared with production in BHI medium supplemented with $2 \%$ sucrose. Interestingly, biofilm formation in media with either 1 or $2 \%$ sucrose content was drastically diminished by L. pentosus $13-4$ and $L$. crispatus LCR01, compared with that in media with other LAB treatments. This difference is due to co-aggregation of the probiotic strains their competition with pathogens for binding sites, which is central to biofilm formation [31]. On the other hand, addition of sucrose to the growth medium resulted in a significant increase in the populations of adherent $S$. mutans cells. The increase in sucrose content led to a reduction in the anti-biofouling capabilities of LAB-SCS [32]. It is probable that resistance of the biofilm to antimicrobial agents is due to the failure of the antimicrobial agent to penetrate the full depth of the biofilm [33].

Biofilm development is characterised by the balance between free cells and attached cells at various steps of its formation. Since simple sugars are present in the environment, the bacterial cells might prefer to remain in the planktonic state and thereby regulate sucrose-dependent cell-cell adhesion and expression of biofilm-formation genes. Thus, the mechanisms that S. mutans uses to adhere to tooth surfaces are important potential targets for anti-cariogenic intervention [32]. Furthermore, most studies that compared the effects of an anti-plaque agent on the unbound GTF activity in planktonic solutions found that the inhibitory effect was much more pronounced in solution than in the immobilised state [34-36]. However, our study showed that gene expression of $g t f C$ was higher in the immobilised state than in solution. Expression of $g t f C$ inhibited by heat-treated LAB-SCS in the immobilised state might be due to the high capability for heat-treated LAB-SCS to diffuse into the immobilised enzymes. Similarly, an amino alcohol molecule, delmopinol, was shown to have a profound inhibitory effect on immobilised GTF compared with that on GTF in solution [36]. However, the inhibitory effect of heat-treated LAB-SCS on $g t f B$ gene expression was not apparent both in immobilised and in planktonic solutions. This phenomenon may be a consequence of insufficient production of $g t f B$ in GTFs by S. mutans BCRC 15255. These results illustrate that GTF activity in S. mutans grown under biofilm conditions is modulated by LAB-SCS. Wu et al. [17] also found two L. salivarius strains from saliva with inhibitory activities on the growth and expression of S. mutans virulence genes to reduce its biofilm formation. Thus, we consider screening different probiotics strains to use as a possible functional food in the prevention or treatment of oral diseases is worthy of our development. 


\section{Materials and methods}

\subsection{Bacterial strains, culture medium and growth conditions}

Samples of 120 LAB strains from the Bioresource Collection and Research Center (BCRC; Hsin-Chu, Taiwan) were screened. These strains were obtained from the faeces of healthy infant and from saliva of healthy adults. Salivary lactobacilli were obtained through the Dentocult ${ }^{\circledR}$ LBB dip-slide (Orion Diagnostica, Espoo, Finland) method [19]. Provisional identification was based on the ability of the isolate to grow in the MRS broth, the gram-positive reaction, rod shape, non-sporing cell morphology and negative catalase reaction. The stock cultures were maintained in $20 \%(\mathrm{w} / \mathrm{v})$ glycerol at $-80^{\circ} \mathrm{C}$. Bacterial cells were anaerobically propagated twice in lactobacilli Man, Rogosa, Sharpe (MRS) broth (DIFCO, Michigan, USA) containing $0.05 \%$ L-cysteine at $37^{\circ} \mathrm{C}$, for $20 \mathrm{~h}$. Spent culture supernatant (SCS) was obtained by centrifugation $\left(10,000 \mathrm{~g}\right.$ for $10 \mathrm{~min}$ at $\left.4^{\circ} \mathrm{C}\right)$ of 20 hour-old LAB culture adjusted to a cell density of $(1-9) \times 10^{9} \mathrm{CFU} / \mathrm{ml}$. The SCS was plated on MRS agar to determine its sterility. The bacterial strains BCRC 15254, 15255 and 15257 of S. mutans were used for the inhibition study. One loopful of each test strain was inoculated into $3 \mathrm{ml}$ of brain heart infusion broth (DIFCO, Michigan, USA), and the resulting suspension was incubated anaerobically at $37^{\circ} \mathrm{C}$.

\subsection{Spot-on-the-lawn antagonism method}

The antimicrobial activity of S. mutans strains BCRC 15254, 15255 and 15257 was tested according to the method described by Kõll-Klais et al. [19]. The antimicrobial activity of lactobacilli (120 strains total: 41 from BCRC, 69 from faeces of healthy infant and 10 from saliva of healthy adults) against the target bacterium S. mutans BCRC 15257 was assessed by the deferred-antagonism method [37]. BHI agar (DIFCO) was used as the top agar (0.7\%) for S. mutans BCRC 15257. Lactobacilli were stab-inoculated on the surface of the bottom MRS agar $(1.5 \%)$, which was then incubated anaerobically for $24 \mathrm{~h}$ at $37{ }^{\circ} \mathrm{C}$ to allow development of visible colonies. Target bacteria were pre-cultivated in their appropriate media and cell suspensions were adjusted to a predetermined optical density (OD $0.10-0.25$ at $600 \mathrm{~nm}$, depending on the target bacteria) to yield confluent growth in the top agar. Thereafter, $5 \mathrm{ml}$ of the melted top agar cooled to $42{ }^{\circ} \mathrm{C}$ was seeded with the pre-cultivated target bacterial suspension $(100 \mu \mathrm{l})$ and then poured over the colonies of lactobacilli. The S. mutans plates were incubated anaerobically at $37^{\circ} \mathrm{C}$ for $24 \mathrm{~h}$ to allow development of inhibitory zones. All tests were performed in duplicate, and results were reported as the mean width of two inhibition zones measured from the edge of the colony of the Lactobacillus strain to the margin of the inhibition zone.

\subsection{Time-kill assay}

The time-kill assay performed to determine the viability of S. mutans exposed to LAB-SCS by using a modification of the method reported by Eckert et al. [38]. S. mutans strains BCRC 15254, 15255 and 15257 were grown to the $\log$ phase and then diluted to $10^{7} \mathrm{CFU} / \mathrm{ml}$ in the growth medium. Mixtures consisting of equal volumes of the target bacteria and a conditioning solution for LAB were prepared. The conditioning solutions included LAB-SCS (strains 13-4 and LCR01) from the $24 \mathrm{~h}$ incubation, neutralised LAB-SCS (adjusted to $\mathrm{pH} 7.0$ with $1 \mathrm{~N} \mathrm{NaOH}$ ), 2- and 4-fold dilutions of LAB-SCS, and LAB-SCS heated for $15 \mathrm{~min}$ at $100^{\circ} \mathrm{C}$ or treated with amylase $(200 \mu \mathrm{g} / \mathrm{ml})($ Sigma, La., U.S.A.) for $30 \mathrm{~min}$ at $37^{\circ} \mathrm{C}$. A control, a suspension of $S$. mutans, was mixed with the same amount of BHI broth. The resulting suspensions were monitored at $0,6,12$ and $24 \mathrm{~h}$ of incubation and then diluted in phosphate-buffered saline (PBS) by serial 10-fold dilutions. Aliquots (100 $\mu \mathrm{L})$ of each dilution were then pour-plated on BHI agar (1.5\%) to determine the bacterial colony counts after 48 $\mathrm{h}$ at $37^{\circ} \mathrm{C}$ under anaerobic conditions. Each assay was performed at least three times.

\subsection{Characteristics of the antimicrobial activity of LAB-SCS}

To determine the substances antagonistic to $L A B$, purification of the protein or lipophilic fraction was performed according to the method reported by Liévin et al. [39]. Ammonium sulphate precipitation was conducted by adding solid ammonium sulphate to the LAB-SCS with continuous 
stirring until the solution reached $80 \%$ saturation. The solution was kept at $4{ }^{\circ} \mathrm{C}$ overnight to allow complete precipitation of the protein and then centrifuged at 10,000 $\mathrm{g}$ for $15 \mathrm{~min}$. The pellet was re-suspended in $2 \mathrm{ml}$ of sterile PBS. The lipophilic fraction was extracted from $20 \mathrm{ml}$ of LAB-SCS with chloroform-methanol solution $(1: 1, \mathrm{v} / \mathrm{v})$. The chloroform layer was dried under a stream of nitrogen and the lipophilic fraction was further tested for antimicrobial activity. The antimicrobial activity against $S$. mutans in the treated samples was determined through the time-kill assay.

\subsection{Tooth degradation}

To assess the ability of oral Lactobacillus pentosus 13-4, Lactobacillus crispatus BCRC 14618 (LCR01) and S. mutans strains BCRC 15254 and BCRC 15255 to degrade teeth, a modified assay based on the method of Nikawa et al. [29] was conducted. A $0.145 \mathrm{~g}$ sample of teeth from Wistar rats was placed in each well of a six-well cell-culture plate (Corning Incorporated, Costar, NY, USA). Each well was inoculated with $150 \mu \mathrm{L}$ of $\mathrm{LAB}$ suspension $\left(3.0 \times 10^{9} \mathrm{CFU} / \mathrm{ml}\right)$ or $S$. mutans suspension $\left(3.0 \times 10^{9}\right.$ $\mathrm{CFU} / \mathrm{ml}$ ). Subsequently, $5.0 \mathrm{~mL}$ of $\mathrm{BHI}$ broth was carefully added and the resulting mixtures were incubated for $0,3,6,12$ or $24 \mathrm{~h}$ at $37^{\circ} \mathrm{C}$. After incubation, the amount of calcium released was measured by using a commercial kit (CA590; Randox, Antrim, UK) according the manufacturer's instructions. The calcium concentration of all samples, including the control (prepared in the absence of bacteria), was calculated by using calcium standards. All assays were independently carried out at least twice, with four trials for each sample.

\subsection{Biofilm formation assay: glass-slide method}

The biofilm-formation assay was performed according to the method of Tahmourespour et al. [40]. To generate S. mutans BCRC 15254 biofilms on a glass slide, $1 \mathrm{ml}$ of $S$. mutans overnight culture $\left(10^{9}\right.$ $\mathrm{CFU} / \mathrm{ml}$ ) was inoculated into a plate containing $25 \mathrm{ml}$ of sterile BHI broth supplemented with $1 \%$ sucrose and onto each of two slides with and without heat-treated LAB-SCS from strains 13-4 and LCR01. The glass slides were washed in detergent solution, rinsed twice with distilled water, air dried, and then autoclaved at $121^{\circ} \mathrm{C}$ for $30 \mathrm{~min}$ before use. The plates were subsequently incubated in an orbital incubator $(100 \mathrm{rpm})$ at $37^{\circ} \mathrm{C}$ for $20 \mathrm{~h}$. The glass slides were then removed from the plates and rinsed twice with $10 \mathrm{ml}$ PBS to remove unattached cells. They were then stained with $2 \%$ crystal violet for $5 \mathrm{~min}$, washed, air-dried, and then photographed by using an inverted microscope with a digital camera (Nikon, TE2000-S). Images showing biofilm accumulation were obtained at a magnification of 200×.

\subsection{In vitro biofilm assay}

A method for assaying biofilm formation of S. mutans BCRC 15254 and BCRC 15257 was conducted according to the method described by Lebeer et al. [41], with minor modifications. The device used for biofilm formation was a platform carrying a 96-well culture plate (GeneDireX, Inc., Flint Place Poway, CA, USA). The device for biofilm formation was placed in its sterile tray filled with $170 \mu \mathrm{l}$ of BHI broth supplemented with $1 \%$ or $2 \%$ sucrose $(w / v)$. Afterward, $10 \mu \mathrm{l}$ of S. mutans (ca. $3 \times 10^{9}$ $\mathrm{CFU} / \mathrm{ml}$ ) was transferred to the wells, which were then co-incubated with LAB strains $13-4$ and LCR01 (cell, SCS, heated cell and heated SCS) for $48 \mathrm{~h}$ or post-incubated after $24 \mathrm{~h}$ at $37{ }^{\circ} \mathrm{C}$ in the presence of $5 \% \mathrm{CO}_{2}$. To quantify biofilm formation, the wells were briefly washed with PBS and the attached bacteria were stained for $30 \mathrm{~min}$ with $200 \mu \mathrm{L}$ of $0.1 \%(\mathrm{w} / \mathrm{v})$ solution of crystal violet in an isopropanol-methanol-PBS mixture (1:1:18, v/v). Each well in the 96-well plate was rinsed with 200 $\mu l$ PBS to remove excess stain. After the plates were air-dried $(30 \mathrm{~min})$, the dye bound to the adherent cells was extracted with $200 \mu \mathrm{l}$ of $30 \%$ glacial acetic acid. The OD at $570 \mathrm{~nm}$ of a $200 \mu \mathrm{l}$ suspension from each well was measured by using an enzyme-linked immunosorbent assay (ELISA) reader (BIO-RAD, model 680).

\subsection{Extraction of total RNA and Reverse-transcription polymerase chain reaction (PCR)}

For the experiment on biofilm generation, $20 \mathrm{ml}$ of $S$. mutans BCRC 15255 culture was placed in each tissue-culture dish $(100 \times 20 \mathrm{~mm})$ (Corning Incorporated, NY, USA) and then cultivated with $15 \mathrm{ml}$ of $\mathrm{BHI}$ broth supplemented with $2 \%$ sucrose at $37^{\circ} \mathrm{C}$ in the presence of $5 \% \mathrm{CO}_{2}$. After $20 \mathrm{~h}$ of 
incubation, the SCS was aspirated from the wells and the biofilm was incubated in $15 \mathrm{ml}$ of fresh BHI broth with $2 \%$ sucrose supplemented with $200 \mu \mathrm{l}$ of the tested LAB and with their heat-treated SCSs. After $20 \mathrm{~h}$ of incubation, cells from the biofilms were dislodged with a sterile cell scraper (Greiner Bio-One $\mathrm{GmbH}$, Frickenhausen, Germany) and transferred to $2 \mathrm{ml}$ micro-centrifuge tubes containing $1.5 \mathrm{ml}$ of TRI Reagent (Sigma-Aldrich, St Louis, MO, USA) and then centrifuged. The RNA-containing supernatant was supplemented with $200 \mu \mathrm{l}$ of 1-bromo-3-chloropropane (Molecular Research Center, Cincinnati, OH, USA), and its upper aqueous phase was precipitated with $500 \mu \mathrm{l}$ of isopropanol. The resulting RNA pellet was washed with $75 \%$ ethanol and re-suspended in water treated with diethyl pyrocarbonate (Invitrogen, Carlsbad, CA, USA). The RNA concentration was determined on a Qubit ${ }^{\circledR}$ fluorometer (Invitrogen, Carlsbad, CA, USA). RNA extraction followed the procedure for planktonic cells. Cells were collected after centrifugation $\left(4,500 \mathrm{~g}, 4^{\circ} \mathrm{C}\right)$ and then immediately re-suspended in TRI Reagent (Sigma-Aldrich). Cell pellets were stored at $-20^{\circ} \mathrm{C}$ until use for RNA isolation.

Complementary DNA (cDNA) was synthesised by using a SuperScript First-Strand Synthesis System kit (Invitrogen, Life Technologies, Carlsbad, CA, USA) according to the manufacturer's instructions. Primer sequences are specified in Table 5. The cDNA samples were stored at $-20{ }^{\circ} \mathrm{C}$ until use. The integrity of the cDNA was assessed by $2 \%$ agarose-gel electrophoresis using $16 \mathrm{~S}$ rRNA gene as control.

\subsection{Statistical analysis}

All the statistical analyses were performed by using SPSS 17.0 software (SPSS Inc., Chicago, IL). Comparisons between data from groups of animals were done by one-way analysis of variance. Duncan's test was performed to determine significant differences. $P$ values of $<0.001$ were considered statistically significant (indicated with symbols in the tables and figures).

\section{Conclusions}

Through this study, it was revealed that L. pentosus 13-4 from oral saliva and L. crispatus BCRC 14618 (strain LCR01) suppress the growth of the cariogenic bacterium S. mutans. However, differences in strains and origins of bacteria and their species-specific properties may also affect the antimicrobial effect of these strains. Both strains may help decrease the risk of dental caries by production of antimicrobial substances such as lipophilic peptides and acidic peptides. We propose that the inhibitory mechanism of Lactobacillus strains against biofilm formation is associated with sucrose-dependent cell-cell adhesion and with expression of biofilm-formation genes. These findings indicate that lactobacilli may play a crucial role as probiotics in oral and dental health.

\section{Acknowledgements}

This study was supported by the Ministry of Science and Technology, Taiwan, R.O.C. NSC 95-2313-B-241-002).

Author Contributions: C.-C.T. designed the study; P.-P.L. performed the experiments and prepared the manuscript. Y.-M.H. analyzed the data.

All authors have read and approved the final version of this manuscript.

Conflicts of Interest: The authors declare no conflict of interest.

\section{References}

1. Seneviratne, C.J.; Zhang, C.F.; Samaranayake, L.P. Dental plaque biofilm in oral health and disease. Chin. J. Dent. Res. 2011, 14, 87-94.

2. Eke, P.I.; Dye, B.A.; Wei, L.; Slade, G.D.; Thornton-Evans, G.O.; Borgnakke, W.S.; Taylor, G.W.; Page, R.C.; Beck, J.D.; Genco, R.J. Update on Prevalence of Periodontitis in adults in the United States: NHANES 2009 to 2012. J. Periodontol, 2015, 86, 611-622.

3. Saha, S.; Tomaro-Duchesneau, C.; Tabrizian, M.; Prakash, S. Probiotics as oral health 
biotherapeutics. Expert. Opin. Biol. Ther. 2012, 12, 1207-1220.

4. Watabe, K.; Nishi, M.; Miyake, H.; Hirata, K. Lifestyle and gastric cancer: a case-control study. Oncol. Rep. 1998, 5, 1191-1194.

5. Wu, T.; Trevisan, M.; Genco, R.J.; Dorn, J.P.; Falkner, K.L.; Sempos, C.T. Periodontal disease and risk of cerebrovascular disease: the first national health and nutrition examination survey and its follow-up study. Arch. Int. Med. 2000, 160, 2749-2755.

6. Baehni, P.C.; Takeuchi, Y. Anti-plaque agents in the prevention of biofilm associated oral diseases. Oral Dis. 2003, 9, 23-29.

7. Wang, W.; Tao, R.; Tong, Z.; Ding, Y.; Kuang, R.; Zhai, S.; Liu, J.; Ni, L. Effect of a novel antimicrobial peptide chrysophsin-1 on oral pathogens and Streptococcus mutans biofilms. Peptides. 2012, 33, 212-219.

8. Senadheera, D.; Cvitkovitch, D.G. Quorum sensing and biofilm formation by Streptococcus mutans. Adv. Exp. Med. Biol. 2008, 631, 178-188.

9. Argimón, S.; Alekseyenko, A.V.; DeSalle, R.; Caufield, P.W. Phylogenetic analysis of glucosyltransferases and implications for the coevolution of mutans streptococci with their mammalian hosts. PLoS One. 2013, 8, e56305.

10. Barnabé, M.; Saraceni, C.H.; Dutra-Correa, M.; Suffredini, I.B. The influence of Brazilian plant extracts on Streptococcus mutans biofilm. J. Appl. Oral Sci. 2014, 22, 366-372.

11. Kreth, J.; Zhu, L.; Merritt, J.; Shi, W.; Qi, F. Role of sucrose in the fitness of Streptococcus mutans. Oral Microbiol. Immunol. 2008, 23, 213-219.

12. Lee, S.H.; Kim, Y.J. A comparative study of the effect of probiotics on cariogenic biofilm model for preventing dental caries. Arch. Microbiol. 2014, 196, 601-609.

13. Prakash, S.; Tomaro-Duchesneau, C.; Saha, S.; Cantor, A. The gut microbiota and human health with an emphasis on the use of microencapsulated probiotic bacterial cells. J. Biomed. Biotechnol. 2011, 2011, 981214.

14. Meurman, J.H. Probiotics: do they have a role in oral medicine and dentistry? Eur. J. Oral Sci. 2005, 113, 188-196.

15. Ahmed, A.; Dachang, W.; Lei, Z.; Jianjun, L.; Juanjuan, Q.; Yi, X. Effect of Lactobacillus species on Streptococcus mutans biofilm formation. Pak. J. Pharm. Sci. 2014, 27, 1523-1528.

16. Salehi, R.; Savabi, O.; Kazemi, M.; Kamali, S.; Salehi, A.R.; Eslami, G.; Tahmourespour, A. Effects of Lactobacillus reuteri-derived biosurfactant on the gene expression profile of essential adhesion genes (gtfB, gtfC and $f t f)$ of Streptococcus mutans. Adv. Biomed. Res. 2014, 3, 169.

17. Wu, C.C.; Lin, C.T.; Wu, C.Y.; Peng, W.S.; Lee, M.J.; Tsai, Y.C. Inhibitory effect of Lactobacillus salivarius on Streptococcus mutans biofilm formation. Mol. Oral Microbiol. 2015, 30, 16-26.

18. Marsh, P.; Martin, M.V. Oral Microbiology. 4th ed. Oxford: Wright 1999.

19. Kõll-Klais, P.; Mändar, R.; Leibur, E.; Marcotte, H.; Hammarström, L.; Mikelsaar M. Oral lactobacilli in chronic periodontitis and periodontal health: species composition and antimicrobial activity. Oral Microbiol. Immunol. 2005, 20, 354-361.

20. Keller, M.K.; Hasslöf, P.; Stecksén-Blicks, C.; Twetman, S. Co-aggregation and growth inhibition of probiotic lactobacilli and clinical isolates of mutans streptococci: An in vitro study. Acta. Odontol. Scand. 2011, 69, 263-268.

21. Teanpaisan, R.; Dahlen, G. Use of polymerase chain reaction techniques and sodium dodecyl sulphate-polyacrylamide get electrophoresis for differentiation of oral Lactobacillus species. Oral Microbiol. Immunol. 2006, 21, 79-83.

22. Annuk, H.; Shchepetova, J.; Kullisaar, T.; Songisepp, E.; Zilmer, M.; Mikelsaar, M. Characterization of intestinal lactobacilli as putative probiotic candidates. J. Appl. Microbiol. 2003, 94, 403-412.

23. Silvia, A., Nakaia, J.K.S. Validation of bacterial growth inhibition models based on molecular properties of organic acids. Int. J. Food Microbiol. 2003, 86, 249-255.

24. Millette, M.; Luquet, F.M.; Lacroix, M. In vitro growth control of selected pathogens by Lactobacillus acidophilus- and Lactobacillus casei-fermented milk. Lett. Appl. Microbiol. 2007, 44, 314-319.

25. Busarcevic, M., Kojic, M., Dalgalarrondo, M., Chobert, J.M., Haertlé, T., Topisirovic, L. 
Purification of bacteriocin LS1 produced by human oral isolate Lactobacillus salivarius BGHO1. Oral Microbiol. Immunol. 2008, 23, 254-258.

26. Tao, Y.; Drabik, K.A.; Waypa, T.S.; Musch, M.W.; Alverdy, J.C.; Schneewind, O.; Chang, E.B.; Petrof, E.O. Soluble factors from Lactobacillus GG activate MAPKs and induce cytoprotective heat shock proteins in intestinal epithelial cells. Am. J. Physiol. Cell Physiol. 2006, 290, C1018-1030.

27. Nase, L.; Hatakka, K.; Savilahti, E.; Saxelin, M.; Ponka, A.; Poussa, T.; Korpela, R.; Meurman, J.H. Effect of long-term consumption of a probiotic bacterium, Lactobacillus rhamnosus GG, in milk on dental caries and caries risk in children. Caries. Res. 2001, 35, 412-420.

28. Seppa, L.; Luoma, H.; Forss, H.; Spets-Happonen, S.; Markkanen, S.; Pelkonen, K. Invasion of Streptococcus mutans and Lactobacillus salivarius in early caries lesions of gnotobiotic rats. Caries. Res. 1989, 23, 371-374.

29. Nikawa, H.; Makihira, S.; Fukushima, H.; Nishimura, H.; Ozaki, Y.; Ishida, K.; Darmawan, S.; Hamada, T.; Hara, K.; Matsumoto, A.; Takemoto, T.; Aimi, R. Lactobacillus reuteri in bovine milk fermented decreases the oral carriage of mutans streptococci. Int. J. Food Microbiol. 2004, 95, 219-223.

30. Marsh, P.D. Dental plaque: biological significance of a biofilm and community life-style. J. Clin. Periodontol. 2005, 32, 7-15.

31. Kolenbrander, P.E.; Palmer, R.J.; Jr Rickard, A.H.; Jakubovics, N.S.; Chalmers, N.I.; Diaz, P.I. Bacterial interactions and successions during plaque development. Periodontol. 2006, 42, 47-79.

32. Shemesh, M.; Tam, A.; Steinberg, D. Expression of biofilm-associated genes of Streptococcus mutans in response to glucose and sucrose. J. Med. Microbiol. 2007, 56, 1528-1535.

33. Crossley, K.B.; Archer, G.; Jefferson, K. 2nd ed. Staphylococci In Human Disease. Oxford: Blackwell Publishing. 2009.

34. Duarte, S.; Koo, H.; Bowen, W.H.; Hayacibara, M.F.; Cury, J.A.; Ikegaki, M.; Rosalen, P.L. Effect of a novel type of propolis and its chemical fractions on glucosyltransferases and on growth and adherence of mutans streptococci. Biol. Pharm. Bull. 2003, 26, 527-531.

35. Koo, H.; Vacca Smith, A.M.; Bowen, W.H.; Rosalen, P.L.; Cury, J.A.; Park, Y.K. Effects of Apismelliferapropolis on the activities of streptococcal glucosyltransferases in solution and adsorbed onto saliva-coated hydroxyapatite. Caries. Res. 2000, 34, 418-426.

36. Steinberg, D.; Beeman, D.; Bowen, W.H. The effect of delmopinol on glucosyltransferase adsorbed on to saliva-coated hydroxyapatite. Arch. Oral. Biol. 1992, 37, 33-38.

37. Morency, H.; Mota-Meira, M.; LaPointe, G.; Lacroix, C.; Lavoie, M.C. Comparison of the activity spectra against pathogens of bacterial strains producing a mutacin or a lantibiotic. Can. J. Microbiol. 2001, 47, 322-331.

38. Eckert, R.; Qi, F.; Yarbrough, DK.; He, J.; Anderson, M.H.; Shi, W. Adding selectivity to antimicrobial peptides: rational design of a multidomain peptide against Pseudomonas spp. Antimicrob. Agents Chemother. 2006, 50, 1480-1488.

39. Liévin, V.; Peiffer, I.; Hudault, S.; Rochat, F.; Brassart, D.; Neeser, J.R.; Servin, A.L. Bifidobacterium strains from resident infant human gastrointestinal microfloraexert antimicrobial activity. Gut. 2000, 47, 646-652.

40. Tahmourespour, A.; Salehi, R.; Kermanshahi, R.K.; Eslami, G. The anti-biofouling effect of Lactobacillus fermentum-derived biosurfactant against Streptococcus mutans. Biofouling. 2011, 27, 385-392.

41. Lebeer, S.; Verhoeven, T.L.; Perea Vélez, M.; Vanderleyden, J.; De Keersmaecker, S.C. Impact of environmental and genetic factors on biofilm formation by the probiotic strain Lactobacillus rhamnosus GG. Appl. Environ. Microbiol. 2007, 73, 6768-6775. 
Table 1. Antimicrobial activity of lactic acid bacteria strains originating from human saliva, infant stool and BCRC against S. mutans BCRC 15254, expressed as inhibition zone values (mm).

\begin{tabular}{cc}
\hline & $\begin{array}{c}\text { Inhibition of target bacteria: zone } \\
\text { values }(\mathbf{m m}), \text { mean } \pm \text { SD }\end{array}$ \\
\hline LAB Strains & S. mutans BCRC 15254 \\
\hline Human saliva & $2.5 \pm 0.00$ \\
$12-1$ & $2.5 \pm 0.00$ \\
$12-2$ & $2.25 \pm 0.35$ \\
$40-2$ & $3.0 \pm 0.00$ \\
11 & $4.5 \pm 0.13$ \\
$13-1$ & $4.8 \pm 0.14$ \\
$13-4$ & \\
Infant stool & $10.25 \pm 0.35$ \\
LA05 & $11.75 \pm 0.35$ \\
Bb12 & \\
\hline BCRC & $8.25 \pm 0.35$ \\
LCR01 & $12.75 \pm 0.35$ \\
LSS01 & $7.25 \pm 0.35$ \\
Bbr-1 & $3.5 \pm 0.71$ \\
11080 & $5.1 \pm 0.14$ \\
12194 &
\end{tabular}

Table 2. Effect of S. mutans BCRC 15254 on the growth by the selected spent culture supernatant (SCS) of lactic acid bacteria (LAB-SCS).

\begin{tabular}{ccccc}
\hline LAB & \multicolumn{4}{c}{ OD $\mathbf{6 0 0} \mathbf{~ n m}$ after incubation time } \\
\cline { 2 - 5 } Strains & $\mathbf{0 ~ h}$ & $\mathbf{6 ~ h}$ & $\mathbf{1 2} \mathbf{~}$ & $\mathbf{2 4} \mathbf{~ h}$ \\
\hline Human saliva & & & & \\
11 & 0.107 & 0.109 & 0.108 & 0.130 \\
$12-1$ & 0.120 & 0.453 & 1.103 & 1.240 \\
$12-2$ & 0.109 & 0.468 & 1.092 & 1.203 \\
$13-1$ & 0.119 & 0.105 & 0.104 & 0.103 \\
$13-4$ & 0.108 & 0.111 & 0.112 & 0.109 \\
$40-2$ & 0.109 & 0.450 & 0.829 & 1.053 \\
\hline Infant stool & & & & \\
LA05 & 0.105 & 0.103 & 0.103 & 0.103 \\
Bb12 & 0.104 & 0.104 & 0.103 & 0.107 \\
\hline BCRC & & & & \\
11080 & 0.103 & 0.116 & 0.119 & 0.589 \\
12194 & 0.104 & 0.104 & 0.115 & 0.261 \\
LSS01 & 0.102 & 0.101 & 0.098 & 0.097 \\
Bbr-1 & 0.106 & 0.103 & 0.103 & 0.106 \\
LCR01 & 0.104 & 0.105 & 0.107 & 0.111 \\
\hline & & & & \\
\hline
\end{tabular}

a The optical density (OD) of $S$. mutans was obtained by measuring the absorbance at $600 \mathrm{~nm}$ after $24 \mathrm{~h}$ incubation. 
Table 3. Inhibition of the LAB-SCS on the growth of S. mutans.

\begin{tabular}{ccccc}
\hline & \multicolumn{3}{c}{ Viable counts of S. mutans $(\log \text { CFU/mL) })^{\mathrm{a}}$} \\
\cline { 2 - 5 } Strains & $0 \mathrm{H}$ & $6 \mathrm{H}$ & $12 \mathrm{H}$ & $24 \mathrm{H}$ \\
\hline S. mutans & & & & \\
BCRC 15254 & 8.653 a & 9.563 & $>9$ & $>9$ \\
BCRC 15257 & 8.415 & 9.161 & 9.883 & 9.816 \\
LAB & & & & \\
11-1 & 7.717 & 7.890 & 8.101 & 8.300 \\
12-1 & 8.653 & 9.659 & $>9$ & $>9$ \\
12-2 & 8.613 & 9.519 & $>9$ & $>9$ \\
13-1 & 8.477 & 5.924 & 6.004 & 6.531 \\
13-4 & 8.315 & 6.843 & 6.860 & 7.555 \\
BCRC 11080 & 8.633 & 8.944 & $>9$ & $>9$ \\
BCRC 12194 & 8.602 & 8.996 & $>9$ & $>9$ \\
LSS01 & 8.512 & 8.690 & 8.732 & $>9$ \\
LCR01 & 8.075 & 5.737 & 6.213 & 7.188 \\
Bbr-1 & 8.113 & 8.044 & 8.642 & 9.600 \\
LA05 & 8.077 & 8.055 & 8.196 & 9.487 \\
Bb12 & 8.103 & 8.112 & 8.077 & 9.267 \\
\hline
\end{tabular}

a Bacteria counts are converted to $\log \mathrm{CFU} \mathrm{mL}^{-1}$

Table 4. Characteristics of the antibacterial activity of LAB-SCS.

\begin{tabular}{llc}
\hline Treatment & & $\begin{array}{c}\text { Viable counts of } S . \\
\text { mutans }(\log \text { CFU/mL) }\end{array}$ \\
\hline Inoculum S. mutans BCRC 15255 & & $7.72 \pm 0.01^{\mathrm{d}}$ \\
Control 13-4-SCS-Heating & $5.72 \pm 0.08^{\mathrm{b}}$ \\
Control LCR01-SCS-Heating & $5.68 \pm 0.9^{\mathrm{b}}$ \\
Ammonium sulphate precipitation & & $6.22 \pm 0.04^{\mathrm{c}}$ \\
Ammonium sulphate precipitation $^{1}$ & 13-4-SCS & $6.06 \pm 0.05^{\mathrm{bc}}$ \\
Chloroform-methanol extraction $^{2}$ & LCR01-SCS & $5.18 \pm 0.04^{\mathrm{a}}$ \\
Chloroform-methanol extraction $^{2}$ & LCR01-SCS & $6.37 \pm 0.07^{\mathrm{c}}$ \\
\hline
\end{tabular}

Experimental conditions are described in materials and methods.

Results are presented as mean \pm SD obtained from three experiments.

${ }^{1}$ Activity in pellet obtained by ammonium sulphate precipitation.

${ }^{2}$ Activity in the chloroform fraction after methanol-chloroform extraction.

Means sharing different superscript letters in a column are significantly different $(\mathrm{p}<0.05)$, compared with inoculum S. mutans.

Table 5. Nucleotide sequences of primers for $g t f B, g t f C$ and $16 S$ rRNA genes.

\begin{tabular}{llcc}
\hline \multicolumn{1}{c}{$\begin{array}{c}\text { Sequence } \\
\left(5^{\prime}-3^{\prime}\right)\end{array}$} & \multicolumn{1}{c}{ Fragment location } & $\begin{array}{c}\text { Accession } \\
\text { number }\end{array}$ & Primer \\
\hline$g t f \mathrm{~B}-\mathrm{F}$ & AGCAATGCAGCCAATCTACAAAT & $1150-1172$ & M17361 \\
$g t f \mathrm{~B}-\mathrm{R}$ & ACGAACTTTGCCGTTATTGTCA & $1224-1245$ & M17361 \\
$g t f C-\mathrm{F}$ & CTCAACCAACCGCCACTGTT & $434-453$ & M22054 \\
$g t f C-\mathrm{R}$ & GGTTTAACGTCAAAATTAGCTGTATTAG & $496-524$ & M22054 \\
16S- rRNA-F & CCTACGGGAGGCAGCAGTAG & $243-262$ & X58303 \\
16S- rRNA-R & CAACAGAGCTTTACGATCCGAAA & $321-343$ & X58303 \\
\hline
\end{tabular}




\section{Figure legends}

Fig. 1 The inhibitory activity of the spent culture supernatant (SCS) from LAB strains L. pentosus 13-1 (A) and 13-4 (B) on the growth of S. mutans BCRC 15257.

Fig. 2 The inhibitory activity of the LAB-SCS with different treatments from strains L. pentosus 13-1 - 13-4 and L. crispatus BCRC 14618 (LCR01) on the growth of S. mutans BCRC 15257.

Fig. 3 The inhibitory activity of the LAB-SCS from strains L. pentosus 13-1 - 13-4 and L. crispatus BCRC 14618 (LCR01) on the growth of S. mutans BCRC 15255 (A) and 15254 (B).

Fig. 4 Calcium release from teeth caused by LAB strains and S. mutans BCRC 15254 and BCRC 15255 .

Fig. 5 The effect of LAB stains on biofilm formation by S. mutans BCRC 15254. (A) a control group (in the absence of SCS from LAB). (B)\&(C) the experimental groups in the presence heated SCS of strains L. pentosus 13-4 (B) and L. crispatus LCR01 (C). The magnification of three images is $\times 100$.

Fig. 6 Inhibition of S. mutans BCRC 15255 on biofilm formation by L. pentosus 13-4 and L. crispatus BCRC 14618 (LCR01). Inhibition of biofilm formation were compared under different LAB culture conditions: i.e., BHI or MRS medium (growth medium for lactobacilli), LAB (live or dead bacteria), LAB-SCS (with or without heating treatment). The results are expressed compared to biofilm formation of S. mutans BCRC 15255 with BHI medium (positive control) (A) in present 1\% sucrose or (B) in present $2 \%$ sucrose, which was taken as $100 \%$ (dotted line). The error bars represent standard deviations of five biological repeats. The data shown are representative of at least three independent experiments.

Fig. 7 PCR detection of the gtf gene in biofilm immobilized and planktonic solution S. mutans using gtfC PCR primer. Lane 1:100 bp ladder, Lane 2 7: normalized using the 16S rRNA gene as a control, Lane 8 10:Represent PCR products amplified from biofilm immobilized of $S$. mutans BCRC 15255, 13-4-SCS, LCR01-SCS, respectively. Line 11 13: Represent PCR products amplified from planktonic solution of S. mutans BCRC 15255, 13-4-SCS, LCR01-SCS, respectively.

Fig. 8 PCR detection of the gtf gene in biofilm immobilized S. mutans using gtfB (A) and $g t f C$ (B) PCR primer. Lane 1 and 8:100 bp ladder (A) and 50 bp ladder (B), Lane 2 6: normalized using the 16S rRNA gene as a control, Lane 9 13:Represent PCR products amplified from biofilm immobilized of S. mutans BCRC 15255 and addition of LAB stains 13-4, 13-4-SCS, LCR01-SCS, LCR01, respectively. Line 7 and 14: Blank control (without cells). 
Fig. 1
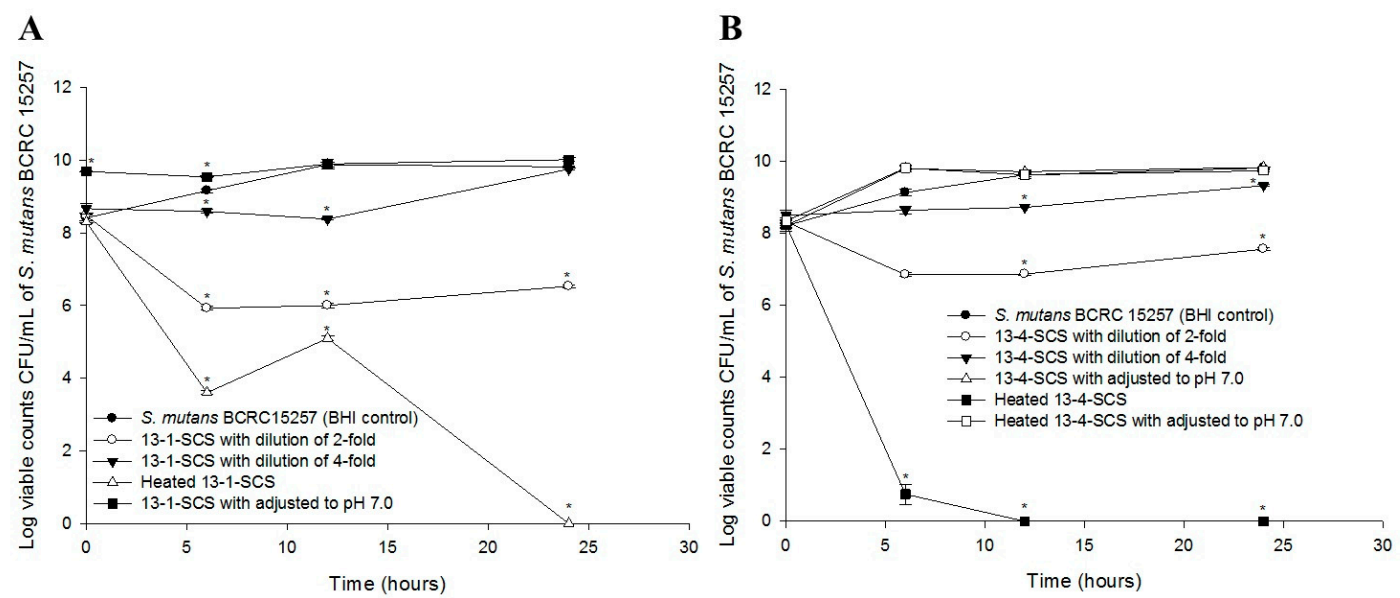

Fig. 2

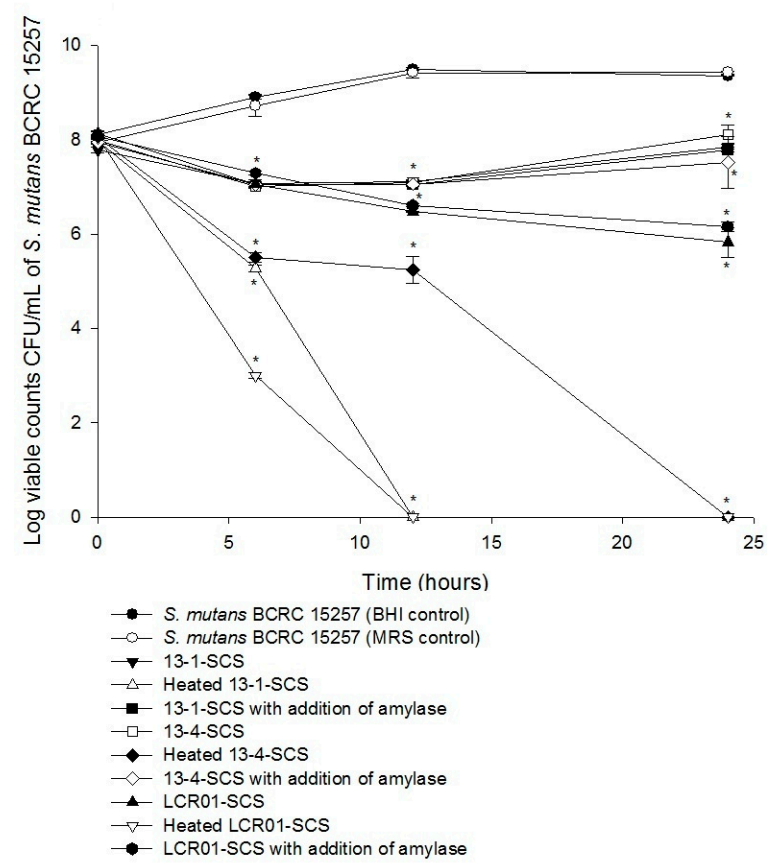

Fig. 3
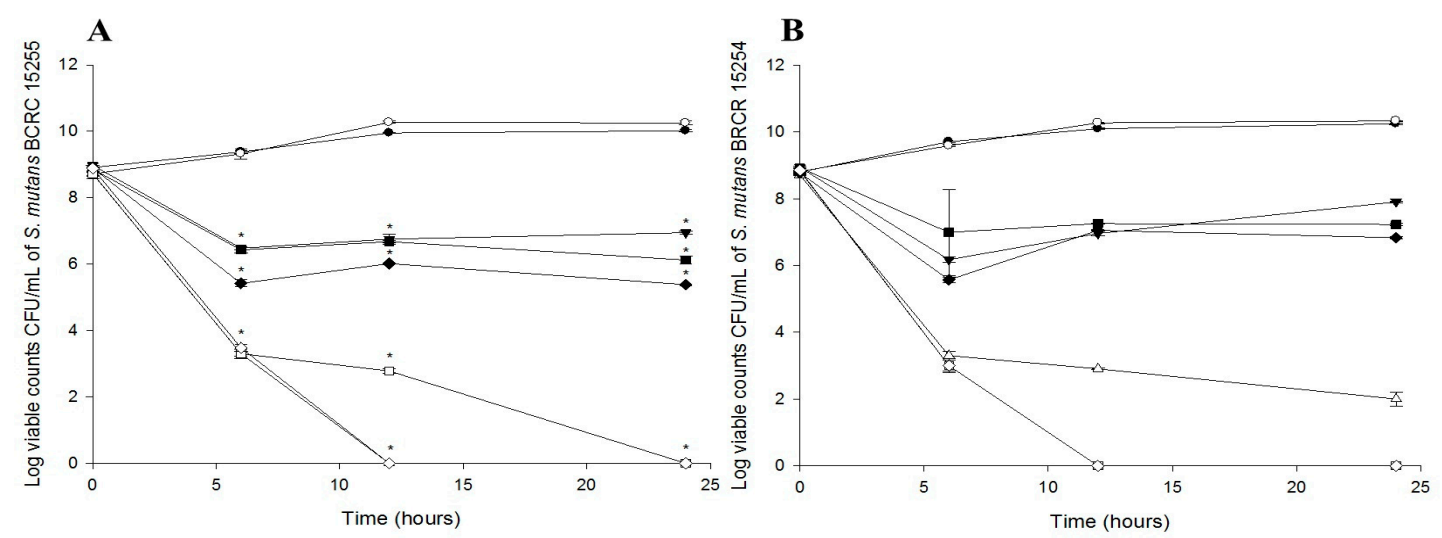

$\rightarrow$ S. mutans BCRC 15255 (BHI control)
$\rightarrow$ S. mutans BCRC 15255 (MRS control)
$\rightarrow$ 13-1-1SCS
- Heated 13-1-SCS
- $13-4$-SCS
- - Heated 13-4-SCS
- LCR01-SCS
- Heated LCR01-SCS

- S. mutans BCRC 15254 (BHI control)

S. mutans BCRC

$\triangle$ Heated 13-1-SCS

- 13-4-SCS

LCR01-SCS-SCS

Heated LCR01-SCS 
Fig. 4

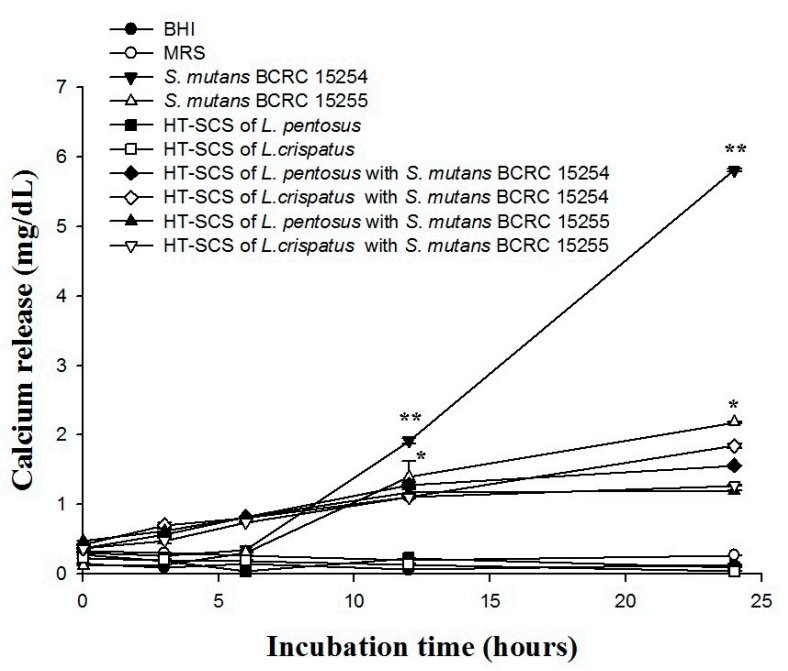

Fig. 5
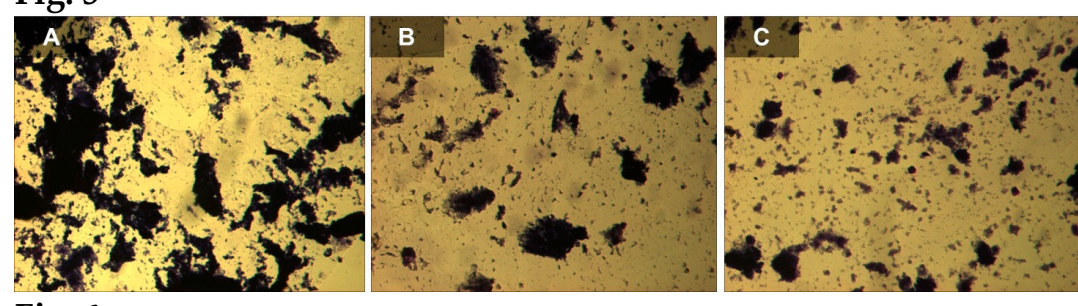

Fig. 6
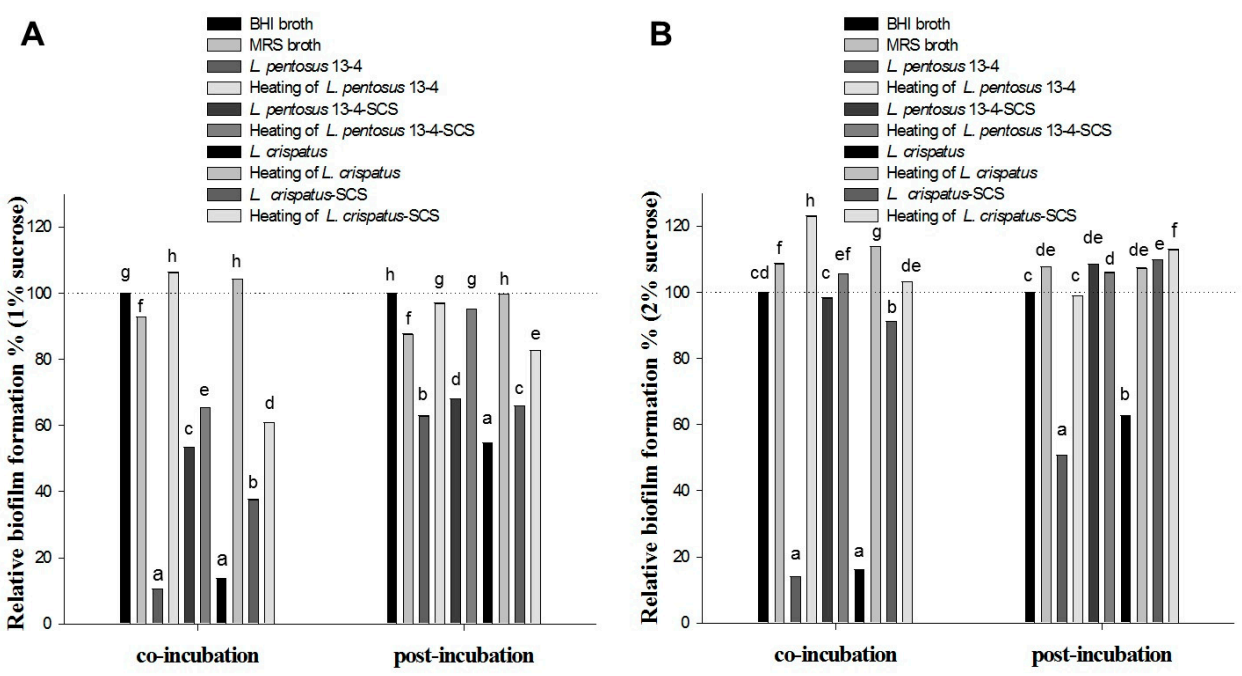

Fig. 7

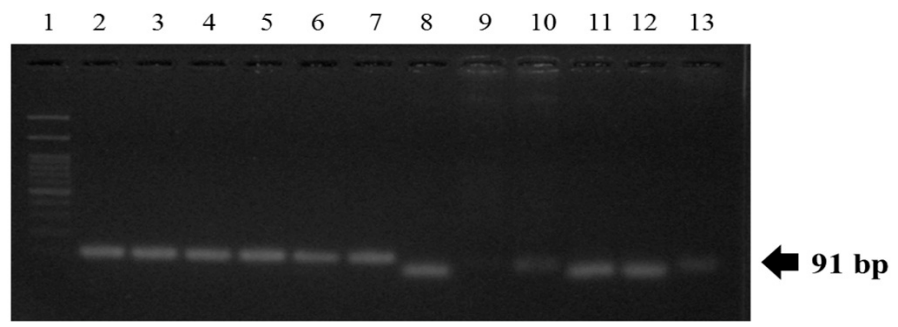


Fig. 8

$\begin{array}{lllllllllllllll}\mathbf{A} & 1 & 2 & 3 & 4 & 5 & 6 & 7 & 8 & 9 & 10 & 11 & 12 & 13 & 14\end{array}$

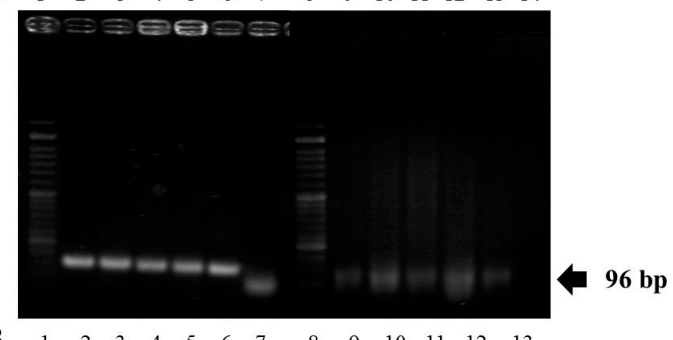

$\begin{array}{llllllllllllll}\text { B } & 1 & 2 & 3 & 4 & 5 & 6 & 7 & 8 & 9 & 10 & 11 & 12 & 13\end{array}$

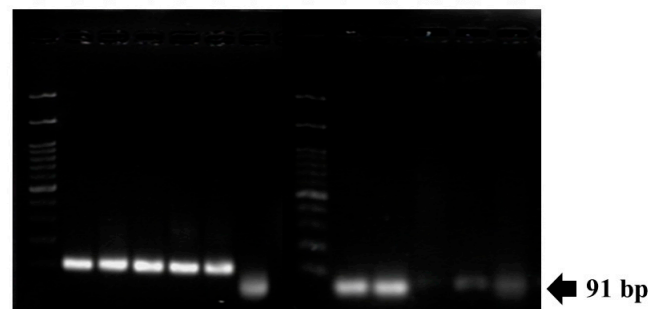

(C) 2016 by the authors; licensee Preprints, Basel, Switzerland. This article is an open access article distributed under the terms and conditions of the Creative Commons by

Attribution (CC-BY) license (http://creativecommons.org/licenses/by/4.0/). 